\title{
Trabajo, identidad y ciudadanía
}

Carolina Quinteros ${ }^{1}$

Departamento de Sociología y Ciencias Políticas UCA, San Salvador

"A mi me llaman en negrito del batey, Porque el trabajo para mí es un enemigo.

El trabajar yo se lo dejo todo al buey, Porque el trabajo lo hizo Dios como castigo" Medardo Guzmán/Alberto Beltrán

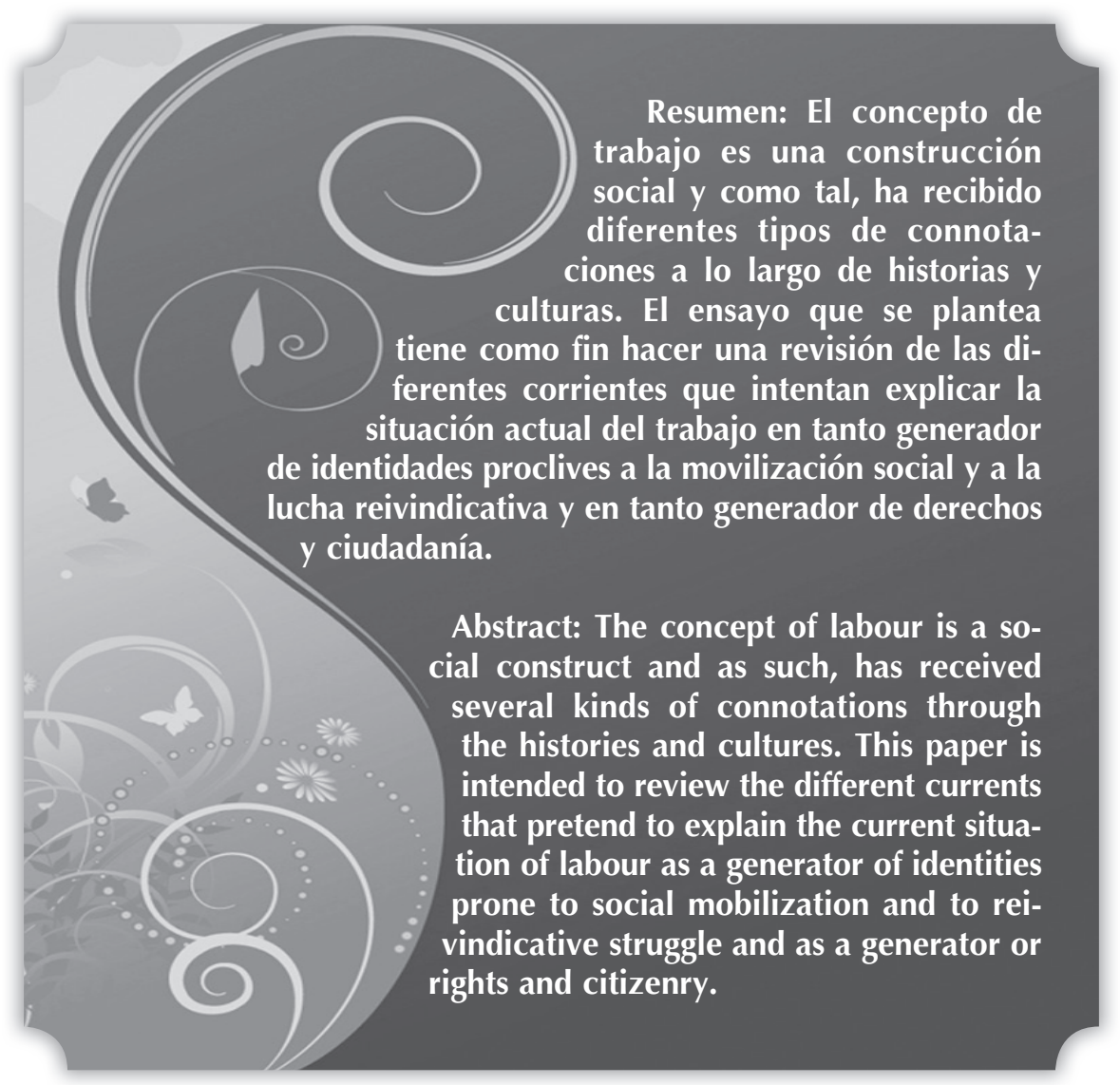


 \\ I concepto de trabajo es una construcción social y como tal, ha recibido diferentes ti- pos de connotaciones a lo largo de historias y culturas. Para los griegos y romanos, el trabajo asalariado (especialmente el manual) era una un asunto indigno. Los esclavos y extranjeros se encargaban de estas tareas y los ciudadanos más bien se dedicaban a las artes, la filosofía o la deliberación política.}

La nobleza medieval católica compartía con el Negrito del Batey la idea que el trabajo era un castigo de Dios a la humanidad y el mismo era considerado poco adecuado para las clases altas y autodenominadas cultas. Paralelamente, el trabajo duro y la vida austera eran valorados y reconocidos por otras confesiones religiosas, tales como los protestantes. Tanto así, que el famoso sociólogo Max Weber Ilegó a reconocer en esa ética religiosa que premiaba la laboriosidad, el ahorro y la reinversión, una chispa impulsora del capitalismo.

Las feministas le añadieron un enfoque novedoso, incorporando en el concepto de trabajo las labores no pagadas realizadas por mujeres y visibilizando el trabajo reproductivo, sumando un enfoque novedoso y extremadamente útil a la comprensión del fenómeno.
Incluso, en términos de naciones, habría que destacar como el imaginario salvadoreño basa buena parte de su identidad nacional y autoestima en la autocaracterización del salvadoreño como persona laboriosa y esforzada. La salvadoreñidad pasa por la identificación con el trabajo independientemente de las clases sociales y del género. Ser salvadoreño, en el imaginario nacional, es ser trabajador y es curioso como más allá, incluso, de las filiaciones políticas, salvadoreños y salvadoreñas se identifican con la frase del poeta Roque Dalton "Los hacelotodo, los vendelotodo, los comelotodo" ${ }^{2}$, para referirse a sí mismos como personas afanosas, aun en la adversidad.

En términos políticos, el trabajo ha servido de base para la promoción de políticas públicas y generación de contratos sociales. Las variaciones sobre su significado han conllevado drásticas consecuencias en la aplicación de políticas sociales. Para la economía clásica, el trabajo tenía un papel claro y clave en la creación de valor y se reconocía la explotación como una condición histórica, pero para los planteamientos neoclásicos de principios del siglo XX, el trabajo se convirtió un factor de producción más, al igual que el capital y la tierra. 
A mediados del siglo $X X Y$ luego de la Segunda Guerra Mundial, nuevamente el concepto de trabajo cambió. En ese momento fue considerado nuevamente un factor importante en la producción y debería ser recompensado y protegido. El trabajo asalariado se convirtió en generador de derechos y los sindicatos fueron reconocidos como actores clave en el contrato social establecido. Pero luego, el enfoque neoliberal revalora el concepto y el trabajo deja de tener un valor en sí mismo y que acredite recompensas para la persona trabajadora. Los derechos laborales no son inalienables ni irrenunciables, ni inherentes a una persona en tanto es trabajadora, sino que deben ser negociados con base en la productividad del trabajador o trabajadora.

Las corrientes analíticas posmodernas también se cuestiona la centralidad del trabajo en la generación de identidades. Sostienen que "la vida está en otra parte": en el ocio, en al consumo, etc. y que son otras las identidades que estarían generando movilización, reclamos de derechos, inclusión y transformaciones.
En estas circunstancias en las que diversas corrientes de pensamiento consideran que el trabajo no genera derechos, ni sus representantes son considerados actores clave del contrato social y que su centralidad en la construcción de identidades susceptibles de movilización está cuestionada, ¿Cuál es el papel del trabajo en la generación de ciudadanías? Más aún, ¿tiene el trabajo algún rol en este proceso? ¿Cuál sería, si no, el cemento de las ciudadanías en la globalización?

El ensayo que se plantea tiene como fin revisar las diferentes corrientes que intentan explicar la situación actual del trabajo en tanto generador de identidades proclives a la movilización social y a la lucha reivindicativa y en tanto generador de derechos y ciudadanía.

El documento no pretende ser conclusivo. Como se verá, más que una discusión acabada, lo que se presenta es una serie de problemas y desafíos para la investigación en Centroamérica acerca de identidades laborales y ciudadanía. Pese a las argumentaciones neoliberales y posmodernas, ambos resultan ser temas más actuales que nunca.

\section{Evolución del concepto de trabajo}

Como sostiene De la Garza (2002) el trabajo ha sido un concepto central en muchas ciencias sociales en los siglos XIX y XX. Este autor destaca que en los enfoques sociales y económicos clásicos, el trabajo tenía un papel claro y clave en la producción de valor. Tanto para Marx como para Ricardo, el trabajo genera valor y es el ele- 
mento esencial para la producción capitalista. Era claro, sobre todo para Marx, que la obtención de ese valor se daba a través de un mecanismo de explotación hacia quienes no poseían medios de producción y la clase trabajadora tenía un papel preponderante en la historia, al ser la llamada a renunciar a esa explotación e implementar un nuevo modo de producción. Estos planteamientos fueron fuente de inspiración para múltiples iniciativas de movilización social, política e incluso militar que tenían dentro de sus símbolos más visibles, al trabajo y a la clase trabajadora como actor fundamental.

Para los planteamientos neoclásicos de principios del siglo $\mathrm{XX}$, el trabajo era un factor de producción más, al igual que el capital y la tierra. Se asumía un equilibrio en el mercado de trabajo, no se mencionaba por ningún lado el tema de la explotación y la clase trabajadora no estaba de ninguna manera, dotada de requerimientos especiales o diferentes de los otros factores de producción.

A mediados del siglo XX y luego de la Segunda Guerra Mundial, nuevamente el concepto de trabajo cambio y con este cambio, las políticas orientadas a los trabajadores $^{3}$. El trabajo fue considerado nuevamente un factor importante en la producción y que debería ser recompensado y protegido. Se reconoce la existencia de intereses contradictorios entre el trabajador y el dueño del capital, pero se sostiene que la misma puede regularse a través de instituciones y políticas públicas de bienestar.

El trabajo asalariado se convierte en generador de derechos tales como seguridad social, pensiones, salud, entre otros. ¿Usted es un trabajador o una trabajadora asalariado (a)? Ergo, tiene derechos y protección por parte del Estado ante los riesgos de la vida: enfermedad, invalidez, desempleo, viudez, etc.

Los sindicatos, como representantes de la clase trabajadora, fueron actores clave de este pacto social y el tripartismo (Estado, Empresa y Sindicatos) se impuso como el ideal de concertación entre los actores que intervienen en la producción.

Si bien esto fue más evidente en los países industrializados, en América Latina pudimos ver algo de este contrato social. Según Lucena (2002), durante el período populista hubo un reconocimiento de la legitimidad de los sindicatos en la participación política, en tanto representantes de una clase social. Eventualmente, la participación política de los sindicatos llevó a un buen sector de los mismos a una relación de cooptación por parte del el Estado (con sus variantes según país), pero seguían siendo un actor clave en el marco político latinoamericano y el trabajo (es- 
pecialmente el asalariado) seguía siendo fuente de derechos, factor de identidad para la movilización de las personas, la búsqueda de balance de poderes $y$, en suma, de ciudadanía.

En Centroamérica, este pacto fue más débil que en los países latinoamericanos con desarrollos industriales más pesados, pero igualmente se vivió un período de auge en el desarrollo de derechos emanados del trabajo asalariado. Pérez Saínz (1998) considera que este proceso fue diferente en los países de la región, siendo el hondureño el que contó con una mayor participación de parte de los sindicatos (fundamentalmente los bananeros de la United Fruit Company) y con un mayor reconocimiento de parte del Estado de la legitimidad de los mismos. Esto se refleja en una legislación laboral con un amplio reconocimiento de los derechos colectivos emanados del trabajo (sindicalización y negociación colectiva), en contraposición al caso costarricense donde, pese a ser prácticamente el único Estado benefactor de la región, la ciudadanía se asentó en los derechos individuales y no en los colectivos.

Pero nuevamente, las cosas cambian. Para finales de los años ochenta se rompe el pacto keynesiano y se inaugura la era neoliberal. Nuevamente, el trabajo es un factor de producción más. Pero, como sostiene Stiglitz (2002) “...el trabajo es distinto a todas las demás mercancías. El ambiente laboral carece de importancia para el acero... El acero no necesita estar motivado para funcionar como insumo. El acero hace lo que se le manda... pero las personas deciden la cantidad de esfuerzo y atención que ponen en el trabajo." Evidentemente, como lo señala el autor, los trabajadores y las trabajadoras no cuentan con la misma capacidad de negociación de los dueños del capital. No es fácil para una persona trabajadora deshacerse de un empleador (a) incapaz, ni le es posible moverse de país a su gusto en caso de no encontrar las suficientes ventajas en algún lado. Adicionalmente, los empleadores pueden actuar de manera colusiva para limitar el acceso al empleo de ciertas personas, como el caso de las listas negras o discriminación hacia ciertos grupos en condición de vulnerabilidad.

En la era neoliberal, el trabajo no vale por sí mismo, sino en tanto sea productivo. Los derechos laborales no son inalienables ni irrenunciables ni inherentes a una persona en tanto es trabajadora, sino que deben ser negociados con base en la productividad del trabajador o trabajadora. Más aun, lo que eran derechos adquiridos, tales como salarios mínimos, se convierten en distorsiones del mercado y deben reducirse a lo mínimo. Las pensiones resultarían impuestos que encarecen el costo de la mano de 
obra produciendo desempleo; y los derechos de sindicalización y negociación colectiva, una demostración del poder monopolístico de los sindicatos.

Incluso, desde un punto de vista que no podría catalogarse como neoliberal, Castells (1997) sostiene que "probablemente el Estado de Bienestar debería ser financiado en base al presupuesto general del Estado, por vía impositiva, y no por contribuciones de trabajadores y empresas, puesto que ello grava la creación de empleo".

En efecto, las políticas económicas y sociales en los últimos tienden a flexibilizar las condiciones de trabajo y a desregular los derechos sociales que habían tenido como fuente, el trabajo asalariado, por el solo hecho de ser considerado trabajo.

Sin embargo, estos parecen más bien presunciones ideológicas que datos salidos de la realidad. Como señala Stiglitz en el documento mencionado, existen estudios que muestran que las leyes de salario mínimo no afectan en modo adverso el empleo.

Adicionalmente a toda esta temática, desde las corrientes analí- ticas posmodernas, también se cuestiona la centralidad del trabajo en la generación de ciudadanía. Sostienen que "la vida esta en otra parte", en el mundo de la vida, en el ocio, en al consumo, etc. y que son otras las identidades que estarían generando movilización, reclamos de derechos, inclusión y transformaciones. Otros autores, llevan sus apreciaciones sobre el trabajo a los extremos y Ilaman a este momento, "El fin del Trabajo" o a la "Era del acceso" (Rifkin, 1996 y 2002)

En el momento histórico en que nos encontramos los derechos laborales no son prerrogativa de nadie y más bien hay que ganárselos. Pero esa "recompensa", se consigue con base a la productividad individual y no como conquista de una clase o un grupo social. Los sindicatos pierden legitimidad en el nuevo entorno y el trabajo, centralidad en la discusión sobre identidades, movilización y ciudadanía. Castells (1997) manifiesta que "habría que pasar de los derechos sociales del trabajador a los derechos sociales del ciudadano", pero si el trabajo ya no es una fuente de ciudadanía y por lo tanto, de derechos o de inclusión ¿cuál sería el cemento de un nuevo contrato social? ¿Quiénes serían titulares de derechos en la era de la globalización?

\section{Identidad y trabajo}

Si bien el trabajo como fuente de ciudadanía se encuentra cues- tionado en la era neoliberal de la globalización y para muchos no es 
clara la relevancia de éste en la formulación del contrato social, habría que ver qué sucede del lado de las personas que trabajan. En concreto, los trabajadores y las trabajadoras, ¿se sienten sujetos de derechos?, ¿incluidos?, ¿ciudadanos?

Las identidades laborales han sido objeto de estudio desde varias perspectivas. Dos de las corrientes más conocidas serían la escuela marxista y la escuela inglesa. La primera, en su versión más estructural, relacionaría la identidad obrera con la identidad de clase. La clase serían un lugar en la estructura económica que es ocupada por un grupo de personas que comparten roles en el proceso de producción y apropiación del excedente económico. Esta situación se revela en ocasiones a las personas para que actúen en consonancia con sus intereses de clase, y en otras no. Cuando la clase obrera no es conciente de su lugar en la estructura y de sus intereses comunes, se dice que esta enajenada. Por el contrario, cuando reconoce su situación pasaría de "clase en sí" a "clase para sí".

La segunda tendencia, la escuela inglesa, más bien consideraría el tema de las clases sociales como una relación histórica, lo cual implica un proceso fluido. En palabras de Thompson (2009, p. 1): "No veo la clase como una "estructura", ni siquiera como una "categoría" sino como algo que tiene lugar de hecho ( $y$ que se puede mostrar que ha ocurrido) en las relaciones humanas". Y seguimos con otra cita: "...la clase cobra existencia cuando algunos hombres, de resultas de sus experiencias comunes (heredadas o compartidas), sienten y articulan la identidad de sus intereses a la vez comunes a ellos mismos y frente a otros hombres cuyos intereses son distintos de (y habitualmente opuestos a) los suyos".

Desde esta perspectiva, la clase obrera tendría un rol más activo en la determinación de su papel en la historia y a partir del contexto concreto en que le corresponde vivir y realizar sus luchas.

Otros autores latinoamericanos también desarrollaron estudios sobre identidad y clase obrera fueron, según De la Garza (1998) Torcuato di Tella y Tourraine. El primero trabajó sobre las mentalidades obreras y las colocó en relación con la estratificación social e identificaciones grupales con los pares y superiores. Tourraine, por su parte, que coloca el trabajo como central en la construcción de la conciencia obrera y la formación de sujetos históricos. La conciencia obrera implicaría una identidad en tanto sentido de pertenencia, una oposición, en la medida que identifica enemigos y una concepción de la totalidad que implica niveles de acción más allá de la fábrica.

En Centroamérica se encuentran los estudios de Acuña (sin fe- 
cha) y Sandoval (1996) acerca de la formación de identidades obreras en trabajadores de enclaves y artesanos a inicios del siglo XX, y las trabajadoras de la maquila a finales de ese mismo siglo, respectivamente.

En el caso del primero, los estudios identifican, nuevamente, que las identidades obreras se formaron con un grupo de personas heterogéneo. Las diferencias étnicas se vivían de una manera muy marcada y las identidades se forjaron con base en experiencias compartidas, intereses comunes y aun espacios de interacción frecuentes en la fábrica o finca y en los espacios de ocio. Es decir, en una amalgama particular al entorno (taller o finca, urbano o rural) de los mundos laborales y los mundos de la vida.

Los estudios de Sandoval refieren más a la formación de identidades de obreras de la maquila. Según estos estudios, parecería que la formación de una conciencia obrera es menos probable para las más jóvenes y un tanto más factible para los trabajadores y las trabajadoras con más años en la fábrica y con mayor capacitación y/o especialización en ciertas tareas, no fácilmente sustituibles. Otros estudios, muestran que las trabajadoras (especialmente las más jóvenes), antes de verse a sí mismas como explotadas, verían en la maquila la oportunidad de experimentar una situación de emancipación y de liberación contra la sujeción a las autoridades patriarcales a las que se habían visto sujetas. El poder adquisitivo que les dan los sueldos que reciben, aunque éstos sean bajo o muy bajos, así como la posibilidad de hacer vida social fuera de la casa, les permiten cierto nivel de independencia respeto a los padres o compañeros de vida (del Cid, Castro y Rodríguez, 1999).

Por su parte, el PNUD ha desarrollado una vertiente interesante en torno a la identidad y el trabajo para el caso salvadoreño. Acá, la identificación con el trabajo no tiene necesariamente que ver con la formación de una conciencia obrera, sino de una identidad nacional. El ser salvadoreño pasa por el trabajo y la laboriosidad es una de las características más fuertes del imaginario salvadoreño. Sin embargo, esta identificación con el trabajo no va de la mano del reconocimiento de ser sujetos de derechos con los reclamos y la movilización correspondiente, sino más bien, de las responsabilidades. Según este estudio, las personas que protestan por las condiciones laborales y reclaman por mejoras y derechos, tendrían a verse más bien como haraganas (IDH, 2008). La identificación con el trabajo, no necesariamente conlleva a un reconocimiento de ciudadanía, aunque sí consiga generar vínculos y cohesiones nacionales.

Pero el estudio del PNUD es un caso poco común. Los estudios laborales en América Latina han 
estado fuertemente amarados a la vinculación del trabajo con temas sindicales y acción colectiva bajo distintas perspectivas, ya sea en el estudio del surgimiento de la clase obrera y su conciencia (Cobarrubias, 2007); o en la relación de los sindicatos y los partidos políticos y el Estado. Hasta la década de los años ochenta se comenzaron a analizar otros fenómenos tales como mercados de trabajo, informalidad y los análisis del proceso de trabajo, destacando estos últimos la relación entre éste y las formas de lucha obrera. Más recientemente, los análisis se enfocan en la flexibilidad y las condiciones de trabajo, destacando el hecho del desmantelamiento de los derechos adjudicados, desregulación y o flexibilización de derechos colectivos tales como la sindicalización y negociación colectiva (de la Garza, 2007). Los sindicatos, para este momento, efectivamente han perdido poder de negociación y de defensa de derechos que habrían constituido el cemento de la ciudadanía social en América Latina.

De la Garza y otros (2008), mencionan que durante mucho tiempo las identidades eran consideradas como una derivación de las estructuras (a tono con la tendencia en las ciencias sociales hasta los años setenta) o un aspecto psicológico de la personalidad. Pero el surgimiento de los estudios sobre Nuevos Movimientos Sociales (NMS) cambió esta perspectiva en tanto que éstos "...se resistían a ser analizados en forma clásica como resultado de contradicciones principalmente estructurales". Estos cambios estuvieron relacionados con el cambio de los paradigmas estructuralistas y "el desencanto acerca de las potencialidades revolucionarias de la clase obrera clásica".

Los NMS estarían cuestionando la centralidad de los conflictos de clase o de las luchas por el control del excedente. Para estos "nuevos" actores, el centro estaría en las luchas que no necesariamente tienen como centro la disputa por el excedente, sino más bien el reconocimiento a sus identidades y el respeto a derechos que emanan de las mismas. "El Sujeto es una afirmación de libertad contra al poder de los estrategas y sus aparatos, contra el de los dictadores comunitarios" (Touraine, 1997).

En el marco de los NMS el trabajo vuelve a aparecer como un tema de alusión obligatoria en las discusiones sobre identidad, aunque sea para negarle centralidad. Sin embargo, de la Garza y sus colegas identifican una corriente de pensamiento que va aún más allá que los NMS en su aversión sobre las posibilidades del trabajo como generador de identidad. Esta tendencia es catalogada como para-posmoderna. Para sus defensores, el mundo laboral esta fragmentado y flexible, generando condiciones bajo las cuales es imposible la formación de 
biografías comunes y de identidad individual o colectiva. Los mundos de la vida generarían más cohesión que el trabajo y lo que impera es el desarraigo de la condición laboral y los actores colectivos del mundo del trabajo ${ }^{4}$.

Sin embargo, como señalan los autores, la identidad no implica necesariamente homogeneidad. La acción colectiva laboral, el ejercicio de la ciudadanía civil, política y social de trabajadores y trabajadoras, tampoco estaría necesariamente fundada en el orgullo del oficio. Muchos de los movimientos obreros más activos (como los sindicatos de sectores industrializados) se han dado en situaciones de "desafección" por el trabajo... "el marxismo clásico nunca planteó que la conciencia de clase derivaría de la Identidad con el Trabajo, la alienación capitalista implica la no Identidad con el Trabajo y frente a este despojo se abriría la posibilidad de la construcción de los trabajadores como una clase para sí. Los trabajos alienados taylorizados de siglo XX jugaron a favor de una Identidad de clase, que no con su trabajo" (de la Garza y otros, 2008, p. 31).

Ciertamente, como señala De la Garza en otros artículos (1998), ha habido transformaciones en la composición de la clase obrera, en la organización de la producción $y$ en los mercados de trabajo que debe reconocerse. Pero "la sociedad capitalista sigue siendo, a pesar de los planteamientos de Offe, una sociedad de asalariados. Con todo y las transformaciones el trabajo capitalista sigue caracterizado por el comando (aunque con nuevas formas) del capital; por la división del trabajo (aunque diferente a la taylorista) y por la cooperación entre hombres en el proceso productivo para lograr los objetivos de la producción (p.89).

Para este autor, la fragmentación entre el mundo del trabajo y los mundos de la vida ha sido un hecho desde siempre, según se desprendería de los estudios de Thompson para la formación de la clase obrera inglesa. Tourraine (1989), para el caso de América Latina también indica como la acción sindical se entrecruza con las demandas por la democracia, el fin de las dictaduras, se entrecruza con movimientos populares de la más varia índole y desborda las demandas constreñidas al lugar de trabajo y las políticas de empleo.

Asimismo, el hedonismo del consumo tampoco es exclusivo del período actual. Sin embargo, los cambios en el mundo laboral sí presentan desafíos y nuevos problemas teóricos. En sus palabras, “¿Cuál es la importancia actual de la experiencia de trabajo en la constitución de de subjetividades e identidades?".

Si bien, no es posible concluir que hemos Ilegado a la Era del Fin 
del Trabajo, como lo propone Rifkin (1996), en efecto, hay cambios que merecen ser estudiados y presentan desafíos a la comprensión de las identidades obreras, especialmente en lo que concierne a la centralidad o no del trabajo en la definición de identidades personales y colectivas, en la potencialidad del trabajo en generar acción social y para el tema que nos atañe en este ensayo, en la posibilidad que el trabajo sea el cemento de la construcción de ciudadanía, sea ésta en su versión de derechos, en su enfoque sobre integración e inclusión social, o incluso, en tanto posibilidad de balance de poderes.

Algunos de estos nuevos problemas tienen que ver en efecto, con cambios en el mercado de trabajo, en las condiciones del mismo y la presencia de nuevos sujetos

\section{a) Concepto de trabajo}

La mayor parte de los análisis sobre trabajo, identidades, entre otras, han tenido como referencia al obrero hombre asalariado, trabajador formal de empresas de industria pesada. El sesgo es entendible a la luz del desarrollo de las ciencias sociales que en algún momento tuvo un sesgo estructuralista. Para estos planteamientos, la noción de trabajo se relaciona directamente con el trabajo asalariado y, dados los desarrollos tecnológicos de la primera mitad del siglo $\mathrm{XX}$, aun más específicamente, el trabajo asalariado que se realiza de manera taylorista. Se suponía que ese era el trabajo que generaba más valor y plusvalía y que colocaba a los trabajadores y trabajadoras en condición de compartir y organizarse. Además, los análisis de género aún no habían hecho mella en el desarrollo de las ciencias sociales.

Evidentemente, estos planteamientos dejan por fuera una buena parte de la población trabajadora, no solo hoy día, sino incluso en los mismos años en que estos estudios eran realizados. Por un lado, es evidente la omisión a las mujeres y los trabajos productivos y reproductivos que realizan. Por el otro, salta a la vista también que, al menos en América Latina, el trabajo industrial asalariado nunca ha sido la forma predominante de empleo. Mucho menos en Centroamérica.

Adicionalmente, ante los cambios en el mercado de trabajo, esos conceptos no se ajustan a las nuevas realidades. Cada día se observa menos presencia de empleos formales, predominando los que se desarrollan en condiciones precarias, en situación de flexibilidad, en sectores no industriales y con cada vez mayor presencia de población femenina, que no es la típica clase obrera reflejada en los primeros estudios sobre el trabajo. El tipo de trabajo predominante en Centroamérica, es el que conlleva la exclusión, no la inclusión (Pérez Saínz y Mora, 2007). Este trabajo estaría transformando al Trabajador 
y al Ciudadano, en Pobre. Mientras el Trabajador y el Ciudadano son sujetos de derechos individuales y colectivos; el Pobre, en el mejor de los casos, es sujeto de asistencia.

En las sociedades latinoamericanas, cumplir, respetar y proteger los derechos económicos y sociales es visto por muchos como un asunto de buena voluntad de los Estados y no como un tema de exigibilidad a esos mismos Estados. Ya hay muchos avances y posibilidades abiertas en la justiciabilidad directa de los derechos económicos sociales y culturales (Urquilla, 2008), pero la pobreza sigue siendo vista como una situación que si bien es moralmente condenable, no constituye una violación a los derechos humanos.

Por otro lado, no es el trabajo asalariado y fabril el que genera la mayor riqueza. En esto, tienen algo de razón quienes sostienen el declive de la centralidad del trabajo productivo en la generación de riqueza, ya que los sectores más influyentes en los países más ricos, parecen ser los financieros y el capital especulativo. Para los países centroamericanos, la mayor generación de riqueza y aportaciones a las economías vienen por el lado de las remesas. Lo que sostiene nuestras economías no es tampoco es el trabajo fabril, sino los "pobredólares".

El concepto de trabajo debe ser ampliado para dar cabida a estas otras realidades. De la Garza (2008) propone considerar en este afán, una actualización y contextualización histórica que debería tomar en cuenta en primer lugar el cambio del objeto de trabajo. Éste ya no se refiere de manera preferencial a la producción de bienes materiales sino al sector servicios y la producción inmaterial. Este cambio trae de la mano reacomodos importantes en las relaciones de producción. "La producción inmaterial es aquella que no existe separada de la propia actividad de producir y que de manera ideal comprime las fases tradicionales de producción, circulación y consumo en un solo acto. Esta comprensión del proceso económico pone en relación directa en el acto mismo de la producción al productor con el consumidor-cliente, complejizando las relaciones sociales de producción al hacer intervenir a un tercer sujeto de manera inmediata en el proceso de producción junto al trabajador y su patrón" (p. 14).

Por otro lado, esta producción inmaterial se refiere también a que los productos en buena medida no son necesariamente bienes materiales, sino simbólicos, tales como la creación de conocimiento. Aunque en este rubro entrará también el consumo de "artículos de estatus", como las marcas.

En otros escritos (Quinteros, 2005), se argumenta que empresas tales como Liz Claiborne, PhillipsVan Heusen, Sears, JC Penney, Wal- 
Mart, entre otras, basan su éxito comercial en la promoción de su marca y no en la producción de los bienes. Ninguna de estas empresas fabrican la ropa que venden, sino que la encargan a terceros mediante un sofisticado proceso de subcontratación a nivel global, mientras ellas se centran en las actividades de la cadena productiva en las que se generan las mayores ganancias: el diseño y la comercialización.

Para comercializar sus productos, la imagen de la marca es lo que cuenta. Ésta no es un artículo de consumo, sino una experiencia o un estilo de vida y la relación con el producto no se concreta necesariamente a través del valor de uso del bien, sino a nivel simbólico y de conceptos abstractos. Las marcas nos acompañan más allá de la experiencia de comprar y usar un producto y ya son parte de la formación de identidades comunitarias y personales. Según Rifkin (2002. 144-145), nos estamos asomando a una era en la que pagamos más por la experiencia de usar cosas que por el valor y la utilidad que las cosas tienen en sí mismas. "... las relaciones mercantilizadas con los consumidores se convierten en el negocio esencial de los negocios; controlar al cliente es ahora algo tan importante y tan urgente como en tiempos en que dominaba la perspectiva de la manufactura lo fue el control sobre los trabajadores... En el siglo venidero, la organización del consumo será tan importante como en el siglo pasado lo fue la organización de la producción"

Otro aspecto que merece ser actualizado es el de la relación de trabajo ya que ésta ya no se produce exclusivamente entre el trabajador, trabajadora y el patrono (a), sino que el cliente interviene dentro de la actividad misma y ejerce influencias en el proceso productivo, aunque el patrono sigue controlando el proceso y, por supuesto, la generación de valor y ganancias. Más aun, los complejos procesos de subcontratación llevan el control del patrono más allá del espacio físico de la fábrica y hasta el hogar del trabajador o trabajadora, con el trabajo a domicilio e informal.

Pero, además, la relación laboral cambia también en tanto que el proceso de trabajo ya no implica necesariamente la relación cara a cara entre trabajadores o trabajadoras. Los call centers son solo uno de los múltiples ejemplos que podrían citarse sobre este asunto. De hecho, estos lazos inmateriales son los que han brotado en la era globalizada en todos los campos en las relaciones humanas. Desde las comunidades en Facebook y otros similares hasta las redes de activistas transnacionales que en contacto permanente con la Web han generado acciones colectivas muy impactantes sobre temas tales como la ecología, las cumbres mundiales y por supuesto, los derechos laborales. Muchas de estas redes carecen 
completamente de relaciones cara a cara y sin embargo, sus activistas se encuentran fuertemente cohesionados, identificados. Curiosamente, no todos los activistas en temas laborales entran en la categoría de clase obrera o sindical y dentro del movimiento antisweatshop ${ }^{5}$ destacan los grupos de estudiantes, consumidores, ecologistas, activistas en contra de la globalización, etc. (Quinteros, 2008).

De la Garza propone más bien la existencia de "una comunidad simbólica del trabajo que puede tener lazos materiales más o menos fuertes... sentirse parte de esta comunidad del trabajo no depende ya del cara a cara sino de la intensidad subjetiva y material de los lazos" (2000, p. 15).

Otro tema interesante de revisar, a criterio de De la Garza, es la división entre producción y circulación de mercancías (a su juicio la circulación de mercancías también producirían valor) y el papel del capital financiero y especulativo en la generación no sólo de ganancia sino de valor ${ }^{6}$.

Igualmente sugerente son sus acotaciones sobre el trabajo productivo y reproductivo. Múltiples estudios dan cuenta del aporte del trabajo reproductivo y doméstico en la valorización del capital y junto con la subcontratación masiva y la flexibilidad laboral es cada vez más complicado separar lo que es traba- jo de lo que no lo es bajo el punto de vista de la economía clásica.

Estos cambios en torno al trabajo demandarían una reformulación del concepto, comenzando por los actores del proceso de trabajo (habría que incluir al consumidor, como de hecho está incluido en los movimientos antisweatshop), la situación de poder dentro del proceso (el consumidor, nuevamente), el carácter simbólico e inmaterial de los bienes que se producen y comercializan (valor de uso versus valor simbólico), el ámbito físico extra fabril de trabajo (doméstico, informal, a domicilio, en el ciberespacio) y la posibilidad de generación de vínculos solidarios sin relaciones cara a cara.

\section{b) El concepto de trabajador}

No cabe duda que muchos de los estudios sobre identidades laborales tienen en mente a un hombre adulto. Uno de los desafíos en la elaboración teórica acerca de las identidades laborales requiere de revisar también aquellos otros sujetos que no son los clásicos obreros.

Los hombres y las mujeres tienen diferentes maneras de aproximarse al mundo del trabajo. Por mediaciones de las sociedades patriarcales, las mujeres han sido históricamente asignadas al trabajo reproductivo (que no ha sido considerado como trabajo) y los hombres al trabajo productivo, entendiendo esto al estilo de la 
economía neoclásica, como aquél que incorpora valor a los bienes que luego serán intercambiados en el mercado. Pero, aunque los productos del trabajo reproductivo no circulen en el mercado, los estudios de acerca del trabajo doméstico de las mujeres dan abundantes explicaciones de cómo éste contribuye a la reproducción de la fuerza del trabajo, a la valorización del capital y a las economías nacionales, especialmente en economías en las que abundan establecimientos informales con abundante mano de obra familiar no remunerada.

En todo caso, la creciente presencia de las mujeres en el mercado de trabajo presenta desafíos en términos de identidades, tanto para ellas mismas, como para la propia definición de trabajo.

García y Oliveira (2007) resumen cuatro distintas tendencias que han existido a la hora de analizar la presencia de las mujeres en el mercado de trabajo. Una de ellas estaría referida a ver el trabajo remunerado como factor e integración y enfatiza acerca de la importancia de este tipo de trabajo en la superación de la condición de subordinación de las mujeres. Otra postura, Ilamada de marginación, sostiene que el trabajo extradoméstico habría contribuido más bien a empeorar la condición de las mujeres en tanto que se realiza en condiciones de iniquidad respecto al trabajo masculino. La tercera posición centra su análisis en la funcionalidad del trabajo femenino, tanto productivo como reproductivo, para la reproducción del capital, en tanto que contribuiría a mantener salarios bajos. Finalmente, una cuarta perspectiva analiza el trabajo extradoméstico de las mujeres como un factor (entre varios) que podrían contribuir al proceso de superación de las subordinaciones y logran incorporar al análisis dimensiones de clase y subjetividades.

Otros estudios más bien sostendrían que los mandatos de género son tan potentes que la superación de la condición de subordinación es mucho más complicada de lo que se supone y la participación de las mujeres en espacios laborales extradomésticos presenta desafíos teóricos singulares.

Como señala Guadarrama (2007) esta incursión implica un proceso de transiciones y rupturas para la vida de las mujeres, que ponen en tensión sus roles dentro y fuera de la casa, labores productivas y reproductivas, la casa y el establecimiento laboral. Las mujeres son enseñadas a valorarse en tanto madres y esposas. El triunfo de las mujeres es el éxito como madres y la realización de su persona pasa por el hogar. Aun en tiempos de la globalización, lo que se valora en una mujer que trabaja fuera de la casa es el equilibrio entre el trabajo y la familia. No se trata, como apunta Guadarrama, de una doble 
jornada, únicamente, sino de una doble presencia: "...las identidades laborales femeninas se construyen en una relación conflictiva con las identidades de género" (p.14).

Sin embargo, al igual que Oliveira y García, esta autora reconoce que estas tensiones son diferentes para distintos grupos de mujeres, colocando el énfasis en el tipo de trabajo que se realiza. Así, "Esta tensión se experimenta de manera diversa entre las profesionistas para quienes el trabajo aparece como un espacio para la autorrealización y expresión de una vocación profesional, en contraste con las mujeres obreras, empleadas y vendedoras donde prevalece la búsqueda del bienestar del grupo familiar, y de una mezcla del trabajo como sacrificio, pero también de orgullo, que se cristaliza en la imagen de mujer luchadora" (p. 15). Habría que investigar más adelante cuál de estas identidades es más sensible a considerar el trabajo como fuente de derechos y ciudadanía.

\section{Jóvenes}

La adolescencia y la juventud son conceptos desarrollados de forma relativamente reciente. Efectivamente existe un paso de la niñez a la adultez que en casi todas las culturas conocidas, es marcado y celebrado de las más diversas formas y con los más diversos ritos. Las personas jóvenes recibían de sus familias los conocimientos productivos y reproductivos necesarios para iniciar la vida adulta en esa comunidad y el mismo iniciaba sin mayores tardanzas, en cuando el cuerpo humano estuviese apto para dichas tareas (Hopenhayen, 2006). La maternidad y el trabajo productivos iniciaban a edades ahora consideradas tempranas. Como menciona Hopenhayen, "Sólo pensar en todo lo que había hecho Alejandro Magno a la edad juvenil resulta hoy casi inconcebible".

En las sociedades actuales el tránsito de la niñez a la adultez sigue asociado con la incursión en la maternidad/paternidad, mayor autonomía respeto a la familia originaria y la posibilidad de ejercer trabajo productivo a través de la incorporación en el mercado de trabajo. Sin embargo, la complejidad de la vida moderna requiere de mayor preparación para ambos procesos y esto vuelve a ese tránsito (la juventud) aún más largo y difuso.

Algunos autores (Saraví, G. 2006) sostienen que la juventud actual se enfrenta a una acumulación de desventajas y vulnerabilidades que tienen que ver con las escasas oportunidades de superación personal que la sociedad le ofrece y los riesgos de ser excluido (o mejor, no incluidos). Las personas jóvenes deben vérselas con diversas tensiones tales como más acceso a educación, pero un menos acceso a empleo, más acceso a información y menos acceso al poder, más destrezas para la autonomía 
y menos opciones de materializarlas; mejores provisiones de salud pero menos reconocimiento en su morbi-mortalidad específica y una creciente desproporción entre consumo simbólico y consumo material (Hopenhayn, 2006).

Se les ha prometido un mundo de oportunidades, pero las mismas no se concretan, generando tensiones entre las expectativas y las realidades. El empleo, o la falta del mismo podría estar relacionado con comportamientos anómicos en la juventud (el sector más golpeado por el desempleo) en situación de exclusión, ya sea bajo la forma de violencia o conductas transgresoras. Según algunos estudios realizados en la región, la transgresión de normas en la población joven es más frecuente en hogares urbanos en situación de exclusión extrema que en hogares rurales e indígenas donde las dinámicas intrafamiliares son particularmente diferentes de otro tipo de familias y en los que habría una menor exposición al consumismo. "... La existencia de este tipo de conductas transgresoras en los jóvenes responde a un proceso de acumulación de déficits en términos de socialización propios de situaciones de exclusión social" (Pérez Saínz y Mora, 2007, p. 185). Para estos autores, esas situaciones se refieren a dinámicas familiares signadas por la violencia, inasistencia a la escuela, falta de empleo, hiperconsumismo globalizador y presencia de grupos de conductas violentas tales como las maras.

En suma, el empleo un asunto clave a considerar en la formación de identidades juveniles. Asimismo, para el análisis del concepto de trabajo, la consideración de la población joven, sus necesidades y problemáticas son temas que forman parte de las particularidades de una heterogénea población trabajadora.

\section{Sector informal}

América Latina y Centroamérica, particularmente, nunca han experimentado un sector laboral formal mayoritario. El trabajador o la trabajadora asalariada, cubierta por seguridad social es más bien una excepción que una regla para la región.

Sin embargo, este no es un sector homogéneo en absoluto. Las diferencias son notables tanto del lado de las actividades y tipos de establecimiento que se registran como del lado de la fuerza de trabajo que integra este sector. En ese sentido, algunas de las principales diferenciaciones que habría que establecer es por género, etnia y edad de estos trabajadores y trabajadoras. Existen asimismo, diferentes maneras de ver y sentir el trabajo para esta población. Mientras para los hombres podría verse con mayor frecuencia una lógica de acumulación, para las mujeres este trabajo es más bien orientado a la 
satisfacción de las necesidades de las familias. En ambos casos, sin embargo, se comparten situaciones comunes tales como las extensas jornadas salariales que conducen a que algunos autores califiquen esta situación de auto explotación (Menjívar y Pérez Saínz, 1993)

Algunos otros autores (Acuña 1993) valoran este esfuerzo y le asignan algunos significados en la vida de las personas del sector informal. Entre estos valores, se encuentra el individualismo como respuesta a una situación en la que ellos no han recibido apoyos más allá de los esfuerzos propios y en algunos casos familiares. "... (El Estado) es una realidad externa $o$ inerte de la que nada se recibe y de la que hay que protegerse por su voracidad tributaria. Tampoco hay nada que esperar de la solidaridad o de la acción colectiva pues se vive en un mundo dominado por la selección natural... Pese a ello, en este universo "prevalecen la utopía del éxito y la ideología de la independencia laboral" (p.19).

Según los estudios de caso que presentan Acuña y Goldemberg (1993) estas personas se identifican con su trabajo y valoran su esfuerzo positivamente y experimentarían orgullo por su oficio, pero, ¿cómo se construye ciudadanía cuando las personas no esperan nada del Estado y cuando tampoco confían en la acción colectiva?
Además, el sector informal es diverso y sus experiencias laborales asimismo, distintas y las no es recomendable hacer demasiadas generalizaciones al respecto de las experiencias laborales o identidades forjadas a la luz del trabajo. Un estudio realizado en Argentina (Graffina, 2004) acerca de identidades ante diversas trayectorias laborales nos algunas ideas de la complejidad del asunto. La investigación consistió en recoger historias laborales de personas trabajadoras pobres de una ciudad argentina (San Juan) e intentaba conocer cómo se ven a sí mismas, cómo se proyectan al futuro y la valoración que hacen del trabajo como "organizador de sus vidas". Las trayectorias laborales se dividieron en precarias, cuentapropistas, precarizadas, fluctuantes y protegidas.

En las trayectorias precarias las personas presentan una visión fatalista de su destino y de la misma construcción del mundo: en la vida hay ricos y pobres, y a ellos, les tocó ser pobres. El trabajo era simplemente una manera de surtir el pan para su familia. Para los cuentapropistas, el trabajo era una manera de salir adelante en la vida y progresar. El esfuerzo personal puede ser recompensado si se trabaja con empeño, se ahorra y se invierte. Por el lado de los precarizados (desempleados o subempleados de mayor edad, por ejemplo) el futuro es un asunto incierto y existen cuestionamientos acerca de valores que antiguamente 
eran parte de sus vidas, tales como la protección estatal ante los riesgos de la vida. El trabajo protegido que antaño obtuvieron, por ejemplo, comienza a verse como un privilegio y no como un derecho. Las personas en situación fluctuante ven el trabajo como una oportunidad, pero contextualizada en un ambiente de incertidumbres. Finalmente, las protegidas ven su trabajo como una forma de ganarse la vida y de estar resguardados ante los riesgos.

En ninguna de las trayectorias laborales de estas personas apa- reció el sindicato como un actor en su favor. Tampoco el Estado, los partidos políticos o alguna otra institución de la democracia y la modernidad. "Las identidades se forjan sobre todo a partir de otros espacios de sociabilidad más cercanos como la familia, la escuela o el ámbito de actividad laboral donde se establecen relaciones cara a cara que permiten mirarse uno mismo a través del otro". En términos de ciudadanía y trabajo, ¿será el trabajo lo que les acredita como sujetos de derechos o más los limita a ser únicamente sujetos de crédito?

\section{Conclusiones}

El trabajo, en tanto elemento de la ciudadanía refleja una libertad básica, un derecho, un elemento de inclusión social y el reflejo de luchas de colectivos que intentan establecer una forma política de equilibrar el poder.

Sin embargo, el concepto de trabajo ha cambiado y sigue trastocando su significado y su sentido, así como también se modifican las condiciones mismas del proceso del trabajo y las personas que se ve inmersas en el mismo. Los conceptos tradicionales no dan abasto para explicar todo esto y se requiere de enfoques que integren la diversidad de las personas trabajadoras y las diferentes maneras de enfrentarse al proceso de generación de valor en la etapa actual del capitalismo y la globalización.
Pero, más allá de las consideraciones teóricas, ¿es el trabajo una fuente de ciudadanía a estas alturas del siglo XXI?

Hace algunos años, la relación salarial era la base para el reconocimiento de derechos, fuente para los recursos que permitiesen una vida en condiciones de acceso a la herencia social, lugar para la formación de identidades y punto de encuentro y organización social de las personas trabajadoras. Difícilmente esto podría sostenerse ahora. En estos momentos históricos de predominio de relaciones mercantilizadas y de hegemonía de los planteamientos neoliberales, el trabajo ha sido relegado como cemento del contrato social y de la ciudadanía. Pero al mismo tiempo, desconocemos cuál es el sujeto sobre el que 
se erigen las nuevas formas de entender la ciudadanía o si es que este ideal de inclusión, derechos y vida digna para todos es considerado un objetivo para nuestros Estados.

En el contexto actual, los derechos no son prerrogativas de nadie, sino bonos por productividad, privilegios o estorbos en el proceso de acumulación. La superación de la pobreza y la protección ante las vicisitudes de la vida (enfermedad, viudez, invalidez, vejez, etc.) no se realiza por acción estatal ni mediante sistemas solidarios de protección a la ciudadanía, sino mediante la acumulación, ahorro y esfuerzo individual. La organización de los trabajadores y trabajadoras pasa por otras instancias no sindicales y en algunos casos, ni siquiera laborales. Si bien es cierto que el trabajo no ha sido lo único que marca la vida de las personas trabajadoras, en las circunstancias actuales los mundos de la vida parecen tener más elementos de cohesión que el la experiencia laboral en sí misma.

¿Se sienten trabajadores los trabajadores? O colocado en clave de identidad, ¿es el trabajo fuente de identificación, lealtades, organización y movilización social? Si lo vemos en términos latinoamericanos y centroamericanos, debemos coincidir con Tourraine en la consideración de elementos no necesariamente laborales para hablar sobre la organización y movilización de las personas. Los trabajadores y las trabajadoras se funden en luchas feministas, por el medio ambiente, por el agua, por la tierra, entre otros. No es raro encontrar en nuestros países federaciones y confederaciones que encuentran como afiliados a organizaciones de inmigrantes, desempleados, trabajadores y trabajadoras del sector informal, etc.

Centroamérica, que no gozó nunca de procesos de industrialización fuertes y que no contó con un sector obrero empoderado, vio con anticipación la heterogeneidad de la población trabajadora y la multiplicidad de actores, intereses valores y expectativas que se integran bajo la categoría de clase trabajadora. Pese a esta heterogeneidad, se han generado intensas movilizaciones sociales en diversos momentos de la historia centroamericana, ya sea bajo la forma de movimientos populares en contra de la guerra, los golpes de estado, la aprobación de tratados de libre comercio, entre otras causas no directamente ligadas al mundo del trabajo.

Ciertamente, se han registrado movilizaciones realizadas en torno al trabajo asalariado en cada uno de los países, ya sea en el sector bananero o de los trabajadores y trabajadoras del sector público, pero la acción propiamente laboral y sindical, no ha sido la nota dominante de las movilizaciones en los últimos años, ni siquiera en las impresionantes marchas y 
acciones que se dieron en Costa Rica en contra de la ratificación del CAFTA ${ }^{7}$ (Quinteros, Ochoa y Salcedo 2005).

¿Ha logrado el trabajo ya sea en si versión asalariada, doméstica o informal; con relaciones cara a cara o virtuales; con mayor o menor control de los patronos sobre el proceso de trabajo, generar sentido de pertenencia y sentimientos de

\section{Bibliografía}

Acuña Ortega, V. H. (s/f). "Artesanos, obreros urbanos y proletarios de enclaves en Centroamérica en el periodo liberal: Una minoría activa". C.I.H.- U.C.R. San José, Costa Rica.

Acuña y Goldemberg (1993) "Género en la informalidad. Testimonios centroamericanos", San José: FLACSO, 1994.

Castells, M. (1997) "Globalización, tecnología, trabajo, empleo y empresa". La factoría, № 7. Barcelona. http://www.lafactoriaweb. com/articulos/castells7.htm

Covarrubias V. Alejandro (2009). Orientaciones laborales y orientaciones políticas en obreros de América Latina: ¿crisis o reconfiguración de identidades?: evidencia en obreros de Argentina, Brasil, México y Venezuela. CLACSO, Buenos Aires titularidad de derechos en las personas trabajadoras de Centroamérica?

Difícilmente esto pueda responderse sin estudios empíricos acerca de cultura, subjetividades e identidades que tomen en cuenta la heterogeneidad de personas trabajadoras y sus situaciones. Los puntos medulares de la discusión teórica están planteados. Hace falta ver qué nos dice la realidad real.

De la Garza Toledo, E. (2000) "Introducción. El papel del concepto de trabajo en la teoría social del siglo XX". En De la Garza (coord.) Tratado latinoamericano de sociología del trabajo. Fondo de Cultura Económica, México, D. F.

(1998) "Trabajo y Mundos de la Vida" en E. León y $\mathrm{H}$. Zemelman (coords.), "Subjetividad: umbrales del pensamiento social", Barcelona, Antropos. http://docencia.izt. uam.mx/egt/publicaciones/capituloslibros/Trabajos $\% 20 y \% 20$ mundos\%20de\%20vida.pdf tudios laborales en América Latina al inicio del Siglo XXI", Sociología del Trabajo, Número 61, Madrid, España. http:// docencia.izt.uam.mx/egt/publicaciones/articulos/Los\%20estudios $\% 20$ laborales $\% 20$ en $\% 20$ america\%20latina.pdf 


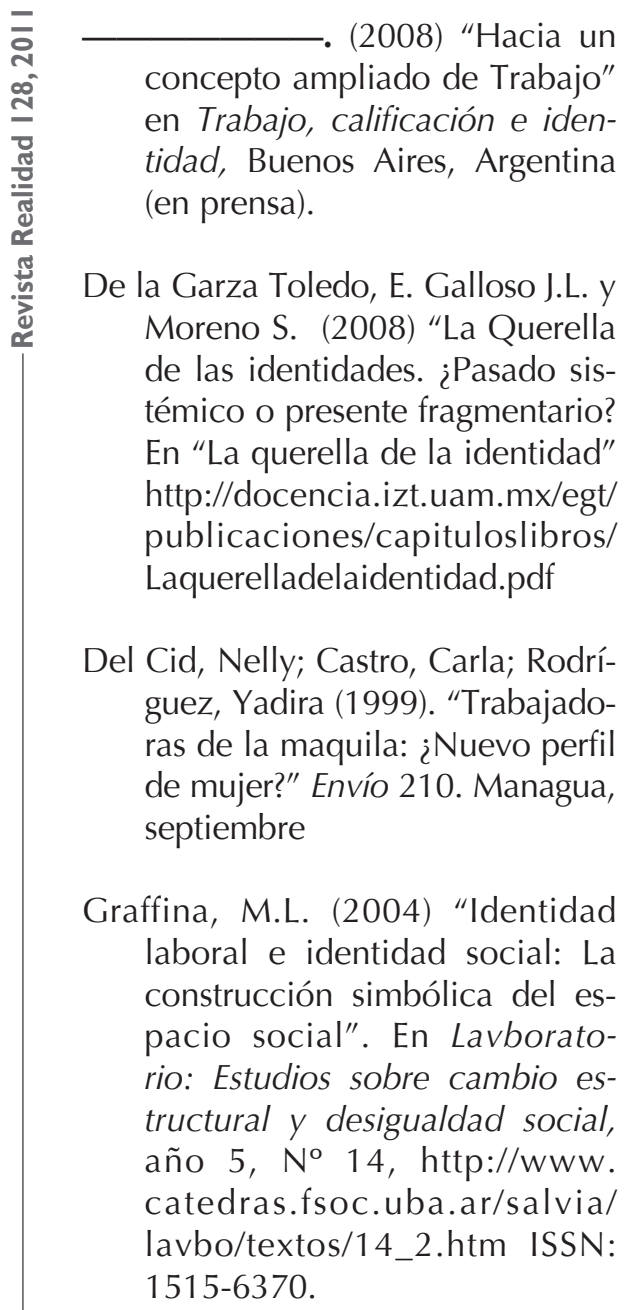

García, B y Oliveira, O. (2007) Trabajo extradoméstico y relaciones de género: una nueva mirada. En "Género, familias y trabajo: rupturas y continuidades. Desafíos para la investigación política".Gutiérrez, María Alicia. CLACSO, Buenos Aires. http://bibliotecavirtual. clacso.org.ar/ar/libros/grupos/ gutierrez/04GarciaOliveira.pdf
Guadarrama, R. (2007) "El territorio de las identidades". En Guadarrama, R. y Torres, J.L (Coords). "Los significados del trabajo femenino en el mundo global. Estereotipos, transacciones y rupturas". Editorial Antropos, Universidad Autónoma Metropolitana.

Guzmán, J. (2009). “Ciudadanía y democracia: Logros y deudas". Ponencia presentada en diplomado sobre identidades, ciudadanía y globalización. INHCA, Managua

Hopenhayn, M. (2006) La juventud latinoamericana en sus tensiones y sus violencias. En Moro, J., Ed. Juventudes, violencia y exclusión: desafíos para las políticas públicas. Programa Nacional INDES-Guatemala, Guatemala

Lucena, H (2002) "El cambio en las relaciones industriales en América Latina". En De la Garza (coord.) Tratado latinoamericano de sociología del trabajo. Fondo de Cultura Económica, México DF.

Marshall, T.H (2004) "Ciudadanía y Clase social" en Marshall y Bottomore, Ciudadanía y clase social. Losada, Buenos Aires

Pérez Sáinz, J.P (1998) “Ciudadanía social y derechos laborales en Centroamérica". Cuaderno de Ciencias Sociales, № 108. FLACSO, San José 1998 (b). 
Pérez Saínz, J.P y Mora. M. (2007) "La Persistencia de la miseria en Centroamérica. Una mirad desde la exclusión social. FLACSO, San José, Costa Rica

Quinteros, C. (2008) “¿Puede humanizarse el mercado? Globalización y sus efectos en las condiciones de trabajo de Centroamérica". GMIES, San Salvador.

(2005) ¿Estamos soñando demasiado? Responsabilidad Social como respuesta para el 2005. GMIES, San Salvador.

Quinteros, C. Ochoa, M. E. y Salcedo. D. "Impacto del Tratado de Libre Comercio entre EEUU y Centroamérica en los Actores Sociales Centroamericanos." Revista Centroamericana de Ciencias Sociales, volumen II, 2005, FLACSO San José, Costa Rica.

Rifkin, J. (1996). El fin del trabajo, Paidós, México DF.

Rifkin, J. (2002). La era del acceso. La revolución de la nueva economía. Paidós Estado y Sociedad, Barcelona

Sandoval, Carlos (1996). Sueños y sudores en la vida cotidiana. Trabajadores y trabajadoras de la maquila y la construcción en Costa Rica. Editorial de la Universidad de Costa Rica, San José.
Saraví, G "Los eslabones de la violencia juvenil: acumulación de desventajas en la transición a la adultez". En Moro, J. (Ed). Juventudes, violencia y exclusión: desafíos para las políticas públicas. Programa Nacional INDES-Guatemala, Guatemala

Stiglitz, J. (2002) "Empleo, justicia social y bienestar de la sociedad", en Revista Internacional del Trabajo, vol. 121, núm. 1-2. OIT.

Sojo, C. (2002) "La noción de ciudadanía en el debate latinoamericano" Revista de la CEPAL, № 76 .

Sojo, C. y Pérez Saínz, J.P. (2002) "Reinventar lo social en América Latina", en Sojo (ed.) Desarrollo Social en América Latina. FLAC$\mathrm{SO}$, San José.

Thompson. E, (2009) "Prefacio", en "La formación de la clase obrera en Inglaterra", en: www. cholonautas.edu.pe / Biblioteca Virtual de Ciencias Sociales

Touraine, Alan (1989) América Latina. Política y sociedad. Espasa Calpe, Madrid.

(1997) ¿Podremos vivir junto? El destino del hombre en la aldea global. Fondo de Cultura Económica. Buenos Aires. 


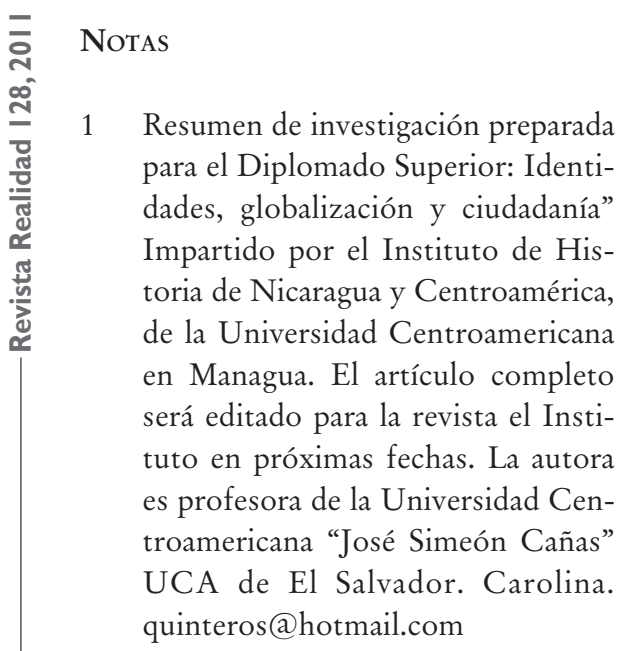

2 "Poema de amor" de Roque Dalton.

3 De forma intencional, en este momento histórico no añado el término trabajadora.

4 Los para-posmodernos le llaman a este fenómeno identidades líquidas y “...parecieran más destinados a alimentar, impresionar e impactar un estado de ánimo propio de la derrota y permanecer en ese Estado... La categoría zombi... es para deslegitimar a quienes planteen lo contrario al fin de los grandes proyectos y sujetos, tachándoles de muertos vivientes; la liquefacción del todo, de la identidad, de la personalidad, el amor, es el debilitamiento de los vínculos por la fragmentación; las "comunidades de guardarropa”, se cambian según la ocasión de la trayectoria laboral y de vida fragmentarias" (de la Garza y otros, 2008, p. 25)
5 Es el nombre que recibe el movimiento de activistas en contra de la explotación en las maquilas de ropa al rededor del mundo.

6 De la Garza hace un señalamiento interesante: Ante la incongruencia entre el valor de una acción en la bolsa y los activos reales de una empresa, “...operaría una fetichización del capital que aparecería como si tuviera capacidades por él solo de reproducirse. Sin embargo, el fetichismo de la economía capitalista no es mera ficción, es la representación de una realidad invertida y con ello no es menos real que la producción. Desde el momento que el capital es una relación social y no un objeto físico (maquinaria o equipo) sino que determinados objetos adquieren el carácter de capital solo porque operan dentro de determinadas relaciones entre los hombres, no es necesario que para que exista capital tenga que encarnar en un objeto físico, ni tampoco para que exista la riqueza tenga que darse desgaste físico de la fuerza de trabajo" (p. 18).

7 Si bien las marchas contra el CAFTA fueron lideradas por un sindicato, las demandas eran por la inminente pérdida de beneficios del estado de bienestar, que en Costa Rica no está necesariamente ligada a las luchas sindicales 